\title{
SEASONAL MOVEMENTS OF BLUE-SPOTTED SALAMANDERS AT PINAWA, MANITOBA
}

\author{
Peter Taylor
}

P.O. Box 597, Pinawa, MB, R0E 1L0, E-mail: <taylorp@granite.mb.ca>

The blue-spotted salamander (Ambystoma laterale) is an inconspicuous, forest-dwelling mole salamander (family Ambystomatidae) that reaches its northwest range limit in southeastern Manitoba. ${ }^{1,2}$ Anecdotal reports of salamanders breeding in a garden pond in Pinawa, MB, and sometimes appearing on streets and in window wells and swimming pools, prompted me to search Pinawa streets for them on rainy nights. Two initial 4-km surveys on the night of 29-30 September 2008 turned up a total of 11 salamanders, demonstrating that this approach can be productive. I therefore conducted similar surveys during the remainder of fall 2008, from spring to fall 2009, and in spring, late summer, and fall 2010. The main aim was to learn about the seasonal timing and favourable conditions for salamander movements. This study coincided with a 2009 survey of the blue-spotted salamander's distribution and conservation status in Manitoba, as described by Hewson \& Watkins (this issue). It also complements a previous review of seasonal activity periods (mostly calling dates and times) for frogs and toads in the Pinawa area. $^{3}$

\section{Study Area}

Pinawa $\left(50.18^{\circ} \mathrm{N}, 95.88^{\circ} \mathrm{W}\right)$ is located in the boreal forest of southeastern Manitoba, adjoining Whiteshell Provincial Park, well within the range of the bluespotted salamander. ${ }^{1,2}$ The town site (current population, ca. 1500) is a mosaic of residential, public, and commercial developments, rocky outcrops, and forest fragments. Cameron Woods is a partly developed, 28-ha block of forest, bounded on the north by Provincial Road 211 and on the south, east, and west by Pinawa streets. The mixed-wood habitat resembles much of the continuous forest surrounding the town, as described recently by Hughes. ${ }^{4}$ It is dominated by trembling aspen, balsam poplar, white birch, balsam fir, and white spruce. Black spruce and black ash occur in moist, lowerlying areas, jack pine on rocky outcrops, and several other tree species are less common or more locally distributed.

My surveys focused mainly on two of the streets bounding Cameron Woods (Cameron Road and a portion of Vanier Avenue) and two residential streets (Devonshire Avenue and Landsdowne Avenue) that radiate away from Cameron Woods. Some of the back yards on the latter streets adjoin some smaller forest fragments. Other streets and rights of way, mostly in more densely developed parts of the town site, were surveyed less frequently. Most Pinawa streets are 8 or $10 \mathrm{~m}$ wide and paved with concrete rather than asphalt.

\section{Methods}

Blue-spotted salamanders emerge in early spring and are active above ground at night, especially during wet weather. ${ }^{1,2,5}$ Surveys were therefore conducted between March and early November, mostly between 21:00 $\mathrm{h}$ and midnight on mild, wet nights with light winds; the main parameters are summarized in Table 1. 
Table 1. Main survey parameters $(2008,2009$, and 2010 combined; 75 surveys).

\begin{tabular}{|l|c|c|c|c|}
\hline & Minimum & Average & Maximum & Total \\
\hline Date (all surveys) & 10 March & --- & 10 November & --- \\
\hline Date (salamanders detected) & 12 April & --- & 2 November & --- \\
\hline Start (hours after sunset) & 1.0 & 3.1 & 7.6 & --- \\
\hline Finish (hours before sunrise) & 2.9 & 7.1 & 11.2 & --- \\
\hline Duration (hours : minutes) & $0: 35$ & $0: 48$ & $1: 30$ & $60: 55$ \\
\hline Distance (km) & 2.4 & 3.2 & 4.7 & 239.3 \\
\hline Live salamanders detected & 0 & 2.44 & 20 & 183 \\
\hline Dead salamanders detected & 0 & 0.15 & 2 & 11 \\
\hline
\end{tabular}

The most frequent route was a 3-km return trip along most of Devonshire Avenue and Cameron Road plus short portions of other streets. I used street lighting, occasionally supplemented with a flashlight, to detect salamanders.

Moisture conditions were noted, using the following six-point scale: 1 , moderate to heavy rain; 2 , light rain; 3 to 6 , not raining but streets were $>90 \%, 50-90 \%$, $10-50 \%$, or $<10 \%$ wet. Air temperature and approximate wind speed, the locations of salamanders, and their behaviour when approached or handled were also noted.
The total length (TL) of each salamander found in 2009 and 2010 was measured or estimated with a precision of 0.2 to $1.0 \mathrm{~cm}$. Snout-to-vent length (SVL) measurement was considered too difficult and intrusive; SVL is about $55-60 \%$ of $T L$ in this species. ${ }^{6}$

\section{Results and Discussion}

Seven surveys were conducted between 29 September and 25 October 2008, 46 between 24 March and 10 November 2009, five between 10 March and 4 May 2010, and 17 between 14 August and 10 November 2010. On three occasions,

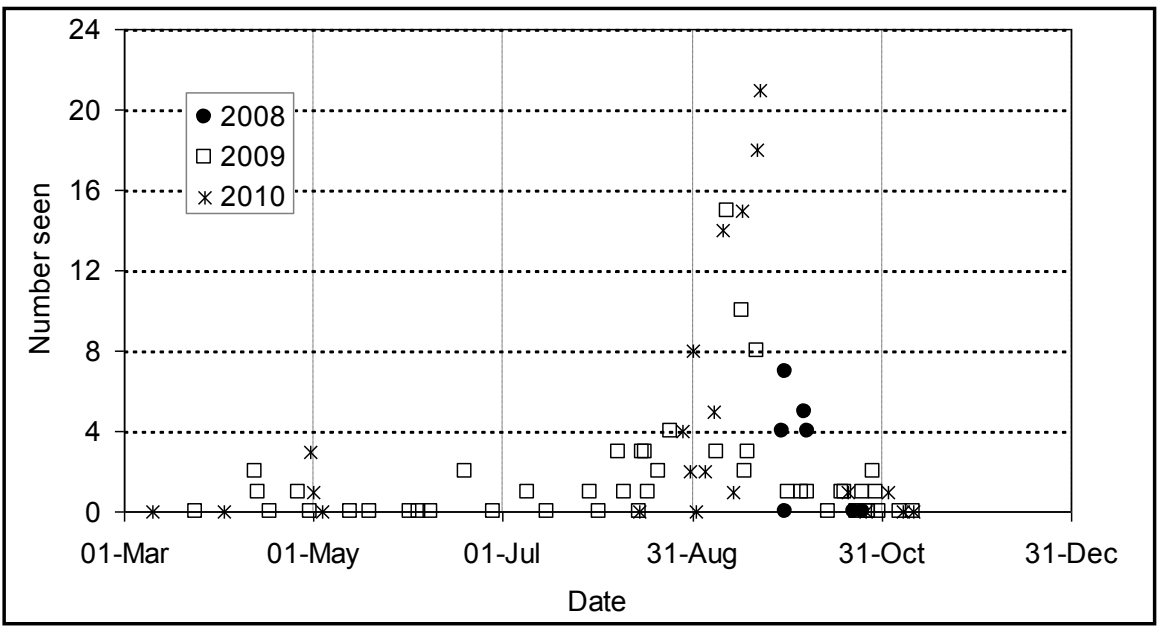

Figure 1. Numbers of blue-spotted salamanders detected during all surveys in 2008, 2009, and 2010. 


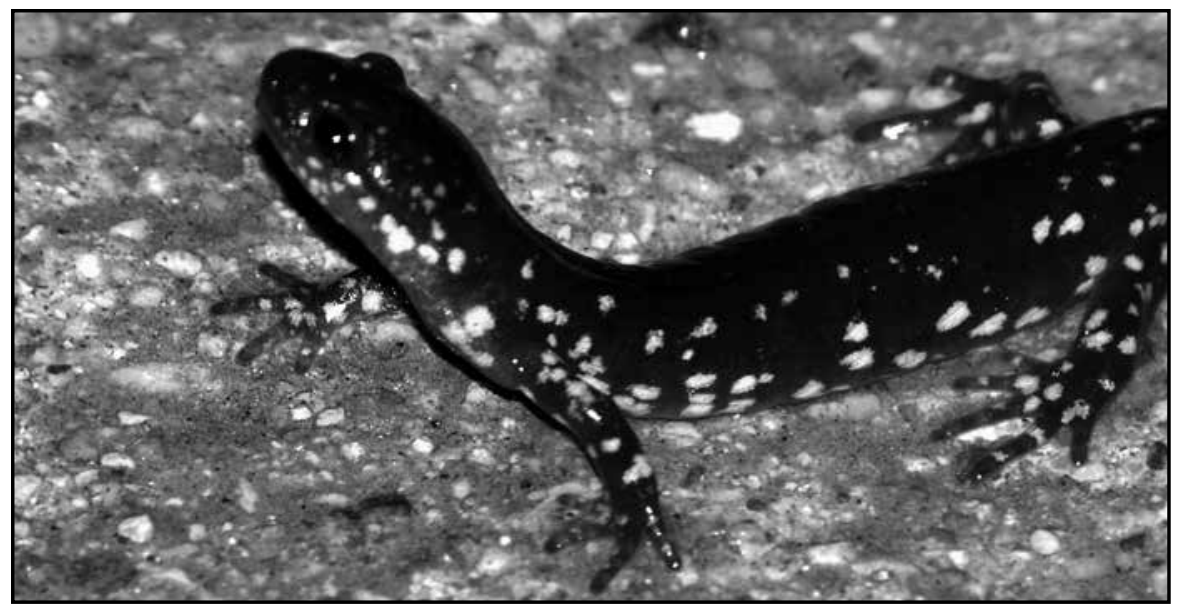

Figure 2. Blue-spotted salamander at Pinawa, Manitoba, 30 September 2008, showing head-up posture. Note the four-toed forefeet and five-toed hindfeet. Peter Taylor

two surveys were done on the same night. Total duration, total distance, and overall results are included in Table 1, and the results of all 75 surveys are shown in Fig. 1. On average, 2.44 live and 0.15 dead salamanders (recent road kills) were detected per survey, including 30 counts of zero. Peak counts were 15 salamanders on 11 September 2009 and 14 to 21 on four surveys between 10 and 22 September 2010. Counts of live and dead salamanders were combined for the data analysis.

All of the salamanders observed were on paved surfaces and not in their normal forest-floor habitat. The surveys therefore sampled actively migrating or dispersing individuals, but numbers and size distributions do not represent the whole population. Several individuals were photographed (see Fig. 2 and front cover), and two road-killed specimens were salvaged and donated to The Manitoba Museum.

\section{Seasonal Occurrence}

The data compiled in Fig. 1 show the following seasonal features: a small spring activity peak between mid-April and early
May, a lull between early May and early June, limited activity between June and mid-August, and a large peak between late August and early October, with further limited activity persisting beyond early snowstorms almost to freeze-up. Significant sequences included six consecutive zero counts between 30 April and 8 June 2009, and 14 consecutive counts of one or more (total 58) between 15 August and 7 October 2009. The 15 highest counts (four or more individuals) were all between 24 August and 7 October.

The timing of the spring peak between mid-April and early May was much as expected from other reports for Manitoba and central Ontario, but numbers were low. ${ }^{15,7,8}$ Blue-spotted salamanders have been described as explosive breeders that arrive at breeding pools in concentrated movements. ${ }^{2,7,8}$ It is possible that brief, concentrated movements from wintering sites to breeding pools passed undetected, or that the main spring migration paths in Pinawa do not cross the survey routes. There was patchy snow cover on the earliest date that salamanders were detected, 12 April 2009, which is also consistent with other reports. ${ }^{1,7,8}$ This 
record preceded the first calling individual wood frogs (Lithobates sylvatica) and boreal chorus frogs (Pseudacris maculata) by 2 days, the first choruses of those species by 10 days, and the first observed movement of northern leopard frogs ( $L$. pipiens) by 18 days.

In an intensive study in Massachusetts, Regosin et al. also noted a summer lull in above-ground movement by blue-spotted salamanders between the breeding season and the post-transformation dispersal of immatures. ${ }^{9}$ However, those authors detected much smaller numbers in fall than spring, which is the opposite of the findings reported here (Fig. 1). This difference may be related to their systematic use of several detection techniques with special attention to the vicinity of breeding ponds, whereas my study was more opportunistic.

\section{Weather Conditions}

Amphibian numbers and activity can vary greatly with prevailing weather conditions, especially moisture levels. To assist comparison with other studies, it is therefore important to mention the unusual weather in 2009 and 2010. Both years were exceptionally wet; the only prolonged dry spells were in September 2009, April 2010, and October 2010. Spring and summer 2009 were also unusually cool, with foliage development, insect emergence, and bird migration all about 2 weeks later than normal; in contrast, spring 2010 arrived unusually early. These conditions likely influenced the timing of salamander emergence, breeding, metamorphosis, and dispersal.

The onset of late-summer salamander dispersal in 2009 followed the year's third highest one-day rainfall $(45.8 \mathrm{~mm})$ on 15 August. Peak numbers were detected shortly after further heavy rains, 58.4 $\mathrm{mm}$ on 8 September and $32.0 \mathrm{~mm}$ on 11 September, punctuating an otherwise dry, warm month. The heavy rain on 15 August also triggered a major dispersal of immature northern leopard frogs, with massive highway mortality, just west of Pinawa. While leopard frogs sometimes appear on roads within minutes of the start of a downpour, the largest numbers of salamanders were typically found immediately after but not during prolonged rains (see below).

Survey results were compiled in three classes $(0,1-2$, and $\geq 3$ salamanders seen) and plotted against temperature and moisture conditions in Fig. 3. This relatively complex figure can be interpreted as follows. High counts ( $>3$ salamanders) were recorded mainly on wet streets shortly after substantial rainfall (moisture code 3 ), less often during rain (codes 1 and 2), and sometimes on dry or partly wetted streets (codes 4 to 6). Whenever large numbers were observed on dry streets, the surrounding wooded habitat was still saturated after previous rains. Low counts ( 1 or 2 salamanders) were recorded mainly under cool conditions $\left(4-10^{\circ} \mathrm{C}\right)$, but also at warm temperatures outside the peak dispersal period (see Fig. 1). Zero counts in Fig. 3 are widely scattered, but with some clustering towards the wettest conditions and lowest temperatures. The observed lower threshold air temperature for salamander movements is about $5^{\circ} \mathrm{C}$, though one was observed making good progress across a street at $4^{\circ} \mathrm{C}$ on 20 October 2010 . This low threshold, the early onset of activity in spring, and continuing movements well into the fall are all consistent with the ability of bluespotted salamanders to remain active at surprisingly low temperatures, although unlike some northern frogs, they cannot survive freezing. ${ }^{5,10}$

\section{Size}

TLs of salamanders found in this study varied from 5 to $13 \mathrm{~cm}$. Most field guides give maximum $T L$ in the $12-14 \mathrm{~cm}$ range 


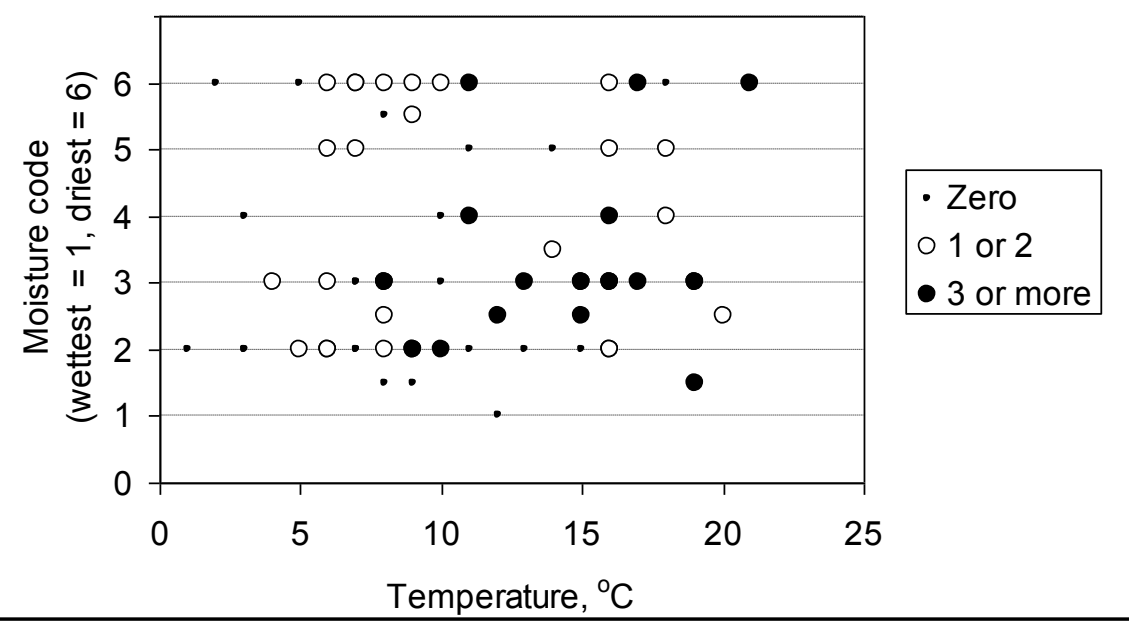

Figure 3. All survey results (numbers of salamanders found), plotted against air temperature and moisture conditions.

for non-hybrid blue-spotted salamanders. In southern parts of their range, bluespotted salamanders frequently hybridize with related species, especially the larger Jefferson salamander (Ambystoma jeffersonianum), but the hybrid zone does not extend to Manitoba. ${ }^{1,2,6,7}$ Hulse et al. reported $T L$ values for newly transformed blue-spotted salamanders of $5.0 \mathrm{~cm}$ in Maine and $6.5 \mathrm{~cm}$ in Nova Scotia. ${ }^{6}$ Size at transformation, however, may vary with food availability and water conditions at the breeding pond. ${ }^{6,12}$

I divided TL measurements for 2009 and 2010 into 9 evenly spaced categories from $5.0 \pm 0.5$ to $13.0 \pm 0.5 \mathrm{~cm}$. Estimated lengths on the $0.5 \mathrm{~cm}$ marks were alternately rounded up and down, so as not to bias the data distribution. Fig. 4 compares the size distribution of salamanders seen during 2009, (a) up to and including 15 August, and (b) on and after 16 August. Sightings up to 15 August, though scarce, included mainly large individuals (9 of 14 , or $64 \%$, were $8.5 \mathrm{~cm}$ or longer). These presumably included fully grown adults, the largest being two $12-\mathrm{cm}$-long individuals observed on 12 April 2009. Salamanders seen on and after 16 August were mainly small (49 of 60 , or $81 \%$, were shorter than $8.5 \mathrm{~cm}$ ), consistent with the dispersal of immature animals. Data for the peak period in 2010 confirmed the earlier movement of large size classes, as shown in Table 2. The percentage of individuals longer than $8.5 \mathrm{~cm}$ declined from $75 \%$ on 28 August -4 September to $10 \%$ on $21-22$ September.

Comparison of size distribution for the peak activity periods in 2009 and 2010 (Fig. 5) showed a slight shift towards larger animals in 2010. While small animals were still in the majority, the peak shifted from the $6-\mathrm{cm}$ to the $7-\mathrm{cm}$ size class, and there was higher representation of large and intermediate size classes. Combined with the relatively large numbers found in 2010 , this suggests good productivity and growth of juveniles, as well as good yearling and adult survival, in the prevailing wet conditions. The sample sizes are small, however, and much more data would be needed before such variations could be verified and interpreted with any confidence. 
Table 2. Summary of salamander measurements, 2010. TL: total length.

\begin{tabular}{|l|c|c|c|c|c|}
\hline & $\begin{array}{c}\text { Aug } 28 \text { to } \\
\text { Sept } 4\end{array}$ & Sept 10 & Sept 16 & Sept 21 & Sept 22 \\
\hline $\mathrm{N}$ (total) & 16 & 14 & 15 & 18 & 21 \\
\hline $\mathrm{N}(\mathrm{TL}>8.5 \mathrm{~cm})$ & 12 & 5 & 3 & 3 & 1 \\
\hline$\%(\mathrm{TL}>8.5 \mathrm{~cm})$ & 75.0 & 35.7 & 20.0 & 16.7 & 4.8 \\
\hline Minimum TL & 6.0 & 6.0 & 6.0 & 5.4 & 6.0 \\
\hline Median TL & 9.3 & 7.0 & 7.2 & 7.2 & 7.1 \\
\hline Maximum TL & 12.0 & 13.0 & 10.0 & 9.8 & 11.0 \\
\hline
\end{tabular}

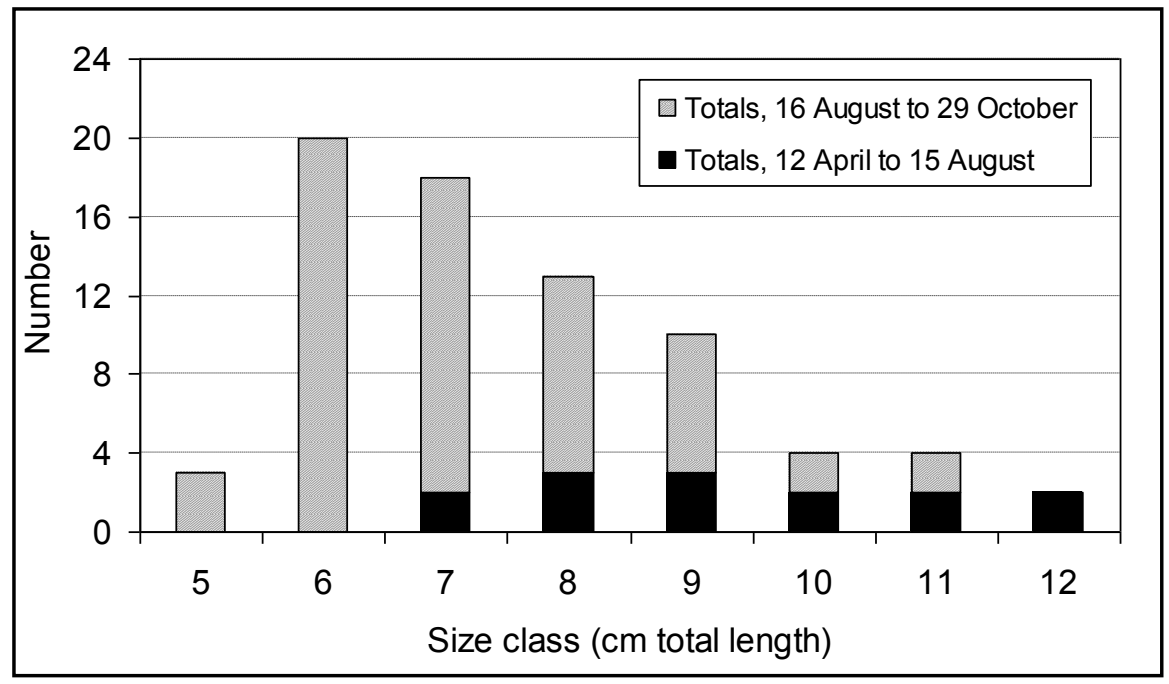

Figure 4. Total lengths of salamanders found between 12 April and 15 August 2009, and between 16 August and 29 October 2009.

This species is reported to take 2 years to reach sexual maturity. ${ }^{2}$ It was not possible to identify yearlings with any confidence in this study, except for two overwintering individuals measuring 6.5 and $7.0 \mathrm{~cm}$ on 26 April 2009 and 1 May 2010, respectively. Spring sample sizes were too small for detailed analysis.

\section{Habitat}

Blue-spotted salamanders use a variety of deciduous and mixed-wood forest habitats, so long as vernal pools (formed by snow melt) or fish-free ponds are available for breeding. ${ }^{1,2,5,11}$ They are reported to be relatively tolerant of selective logging and low-density residential development, although local populations may be threatened by clear cutting and road building near breeding ponds. ${ }^{11}$ Various studies have indicated that this species disperses at least 150 to $200 \mathrm{~m}$ from breeding pools. ${ }^{2,9}$ In the Pinawa surveys reported here, salamanders were found within an irregularly shaped area about $0.9 \mathrm{~km}$ from north to south and 1.3 $\mathrm{km}$ from east to west, but they were not uniformly distributed within this area. 


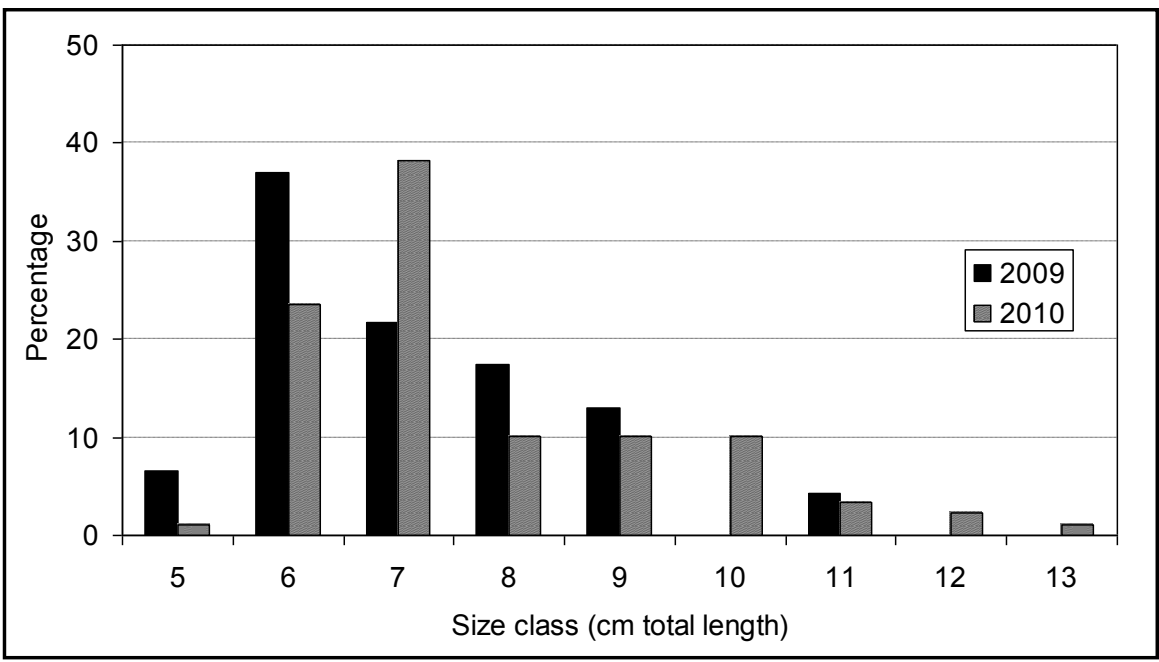

Figure 5. Size distributions (percentages) of salamanders detected during seven surveys between 24 August and 21 September 2009 ( $N=46$ salamanders) and ten surveys between 28 August and 22 September $2010(N=90)$.

I compiled the locations where 72 individual salamanders (at least three per survey) were found on the 13 highest counts in 2008 and 2009. Data from the 2010 surveys were excluded because they were deliberately focused on known "hot spots" and expected peak activity periods. Forest fragmentation and development density are difficult to quantify for the different survey routes, because of the complex street layout and habitat mosaic, but streets were broadly classified as low, medium, and high development density (categories A, B, and C in Table 3). The results show that salamander numbers were highest in or near Cameron Woods (category A), and lowest in areas of high development density and minimal forest cover (category $\mathrm{C}$ ). The numbers of salamanders per kilometre for the three categories are significantly different from those expected for a random distribution throughout the survey area (chi-squared test, $X^{2}=40.99$, df $=2, p<$ $0.1)$. Furthermore, all four salamanders on category $\mathrm{C}$ survey routes were located near isolated forest fragments, which in retrospect would be better classified as category B sub-areas.

Salamander distribution was also non-random along a given street. For example, the largest concentrations in 2010 - as many as six salamanders within a $10-\mathrm{m}$ radius - were found in a portion of Cameron Road near a low-lying ash stand that is suspected to be an important breeding area.

\section{Behaviour and Road Mortality}

Nearly all salamanders were stationary when first observed on the street surface; the straight body and tail, with head slightly raised, provided a distinctive search image (Fig. 2). Five salamanders were encountered walking across streets with a characteristic, side-to-side, undulating (standing wave) motion that is constrained by their sprawling posture. ${ }^{12,13}$ Reactions of individual salamanders to touching and handling were generally most lively in mild, wet conditions and most lethargic in cool, dry conditions. When sufficient water was present on the road, lively individuals 
Table 3. Analysis of the 13 highest salamander counts in 2008 and 2009 by location. See text for a description of categories A, B, and C.

\begin{tabular}{|l|l|l|l|l|l|}
\hline Location & Category & Number & $\begin{array}{l}\text { Distance, } \\
\mathrm{km}\end{array}$ & $\begin{array}{l}\text { Number per } \\
\mathrm{km}\end{array}$ & Description \\
\hline $\begin{array}{l}\text { Cameron } \\
\text { Rd. }\end{array}$ & A & 42 & 13.1 & 3.20 & $\begin{array}{l}\text { Extensive woods with } \\
\text { discontinuous residential } \\
\text { development on both } \\
\text { sides of the street. }\end{array}$ \\
\hline $\begin{array}{l}\text { Landsdowne } \\
\text { Ave. }\end{array}$ & B & 6 & 3.0 & 1.97 & $\begin{array}{l}\text { Perpendicularto Cameron } \\
\text { Woods with continuous } \\
\text { residential development } \\
\text { on both sides, backing } \\
\text { onto smaller forest } \\
\text { fragments. }\end{array}$ \\
\hline Vanier Ave. & B & 7 & 4.3 & 1.63 & $\begin{array}{l}\text { Adjoining Cameron } \\
\text { Woods; mostly open } \\
\text { public reserve and } \\
\text { residential development } \\
\text { on the other side. }\end{array}$ \\
\hline $\begin{array}{l}\text { Devonshire } \\
\text { Ave. }\end{array}$ & B & 13 & 9.9 & 1.31 & $\begin{array}{l}\text { Similar to Landsdowne } \\
\text { Ave. but extending } \\
\text { farther from Cameron } \\
\text { Woods. }\end{array}$ \\
\hline $\begin{array}{l}\text { Elsewhere } \\
\text { in Pinawa }\end{array}$ & C & 4 & 16.2 & 0.25 & $\begin{array}{l}\text { Mostly higher-density } \\
\text { development with few } \\
\text { forest fragments. }\end{array}$ \\
\hline
\end{tabular}

escaped with a rapidly undulating (propulsive wave) motion, sometimes called anguilliform (eel-like) locomotion.

Salamanders adopt a wide variety of defensive postures, often coupled with the secretion of noxious substances, to deter potential predators. ${ }^{14}$ Collicutt noted that he was unable to elicit such a response in blue-spotted salamanders. ${ }^{5}$ Only about six small individuals of the 183 live salamanders I encountered adopted a tail-raised posture when approached.

Most of the salamanders that did not escape to the roadside were transferred by hand to the nearest vegetative cover. This brief handling seemed preferable to leaving them exposed to traffic or possible disorientation and dehydration.
The low number of road kills and obvious injuries (combined, about $10 \%$ of the salamanders found) is encouraging, but dead salamanders are often badly damaged and difficult to detect.

\section{Conclusions}

Blue-spotted salamanders proved to be surprisingly easy to find under street lighting in areas of low-density housing adjoining large fragments of mixed boreal forest. The peak late-summer movement involved dispersal of both adult and immature individuals, with larger animals moving mainly in the early phase of this peak; spring movements were barely detected. Although obviously limited to areas with suitable streets and lighting, the methods used in this survey may be helpful in detecting salamanders at other 
forest communities, and may complement the diurnal searching methods described by Hewson \& Watkins (this issue).

While the Cameron Woods forest fragment appeared to be key habitat in the current study, it is similar to much of the continuous boreal forest surrounding Pinawa. Some local habitat loss to housing development, though regrettable, is therefore probably not significant for conservation of blue-spotted salamanders at the regional or provincial level. The species' status as a member of the Manitoba fauna, though geographically limited, appears to be relatively secure (Hewson \& Watkins, this issue).

\section{Acknowledgements}

I thank Nancy Bremner for the initial observations that prompted this study, Reto Zach and Jim Betteridge for other incidental observations, Shauna Hewson and Bill Watkins for helpful discussions and for sharing their findings, Randy Mooi and Janice Klapecki for information on specimens in The Manitoba Museum, and Reto Zach and a reviewer for constructive comments on draft manuscripts. Finally, I thank Sharon Taylor for encouraging me to study our little four-legged neighbours.

1. Preston WB (1982) The Amphibians and Reptiles of Manitoba. Manitoba Museum of Man and Nature, Winnipeg, MB.

2. Brodman R (2009) Ambystoma laterale Hallowell, 1856, blue-spotted salamander. Modified from: Lannoo M (ed) Amphibian Declines: the Conservation Status of United States Species, University of California Press, Berkeley, CA. In: Amphibiaweb: Information on amphibian biology and conservation [web application]. Available at: <http://amphibiaweb.org/>.
3. Taylor $P$ (2006) Calling periods for frogs and toads near Pinawa, Manitoba, with an update on Mink Frog and Green Frog distribution. Blue Jay 64:44-55.

4. Hughes M (2009) Species diversity of dragonflies and damselflies (Odonata) at a Manitoba pond. Blue Jay 67:242-248.

5. Collicutt D (2009) Blue Spotted Salamander! Online essay. Available at: <http://www.naturenorth.com/ spring/creature/bluespot/Fblspot.html>.

6. Hulse AC, Mccoy CJ, Censky EJ (2001)Amphibians and Reptiles of Pennsylvania and the Northeast. Cornell University Press, Ithaca, NY.

7. Lowcock LA, Griffith H, Murphy RW (1991) The Ambystoma jeffersonianum-laterale complex in central Ontario: ploidy structure, sex ratio, and breeding dynamics in a bisexual-unisexual community. Copeia 1991:87-105.

8. Lowcock LA, Griffith H, Murphy RW (1992) Size in relation to sex, hybridity, and breeding dynamics in central Ontario populations of the Ambystoma jeffersonianum-laterale complex. Journal of Herpetology 26:46-53.

9. Regosin JV, Windmiller BS, Homan RN, Reed JM (2005) Variation in terrestrial habitat use by four pool-breeding amphibian species. Journal of Wildlife Management 69:1481-1493.

10. Storey KB, Storey JM (1986) Freeze tolerance and intolerance strategies of winter survival in terrestriallyhibernating amphibians. Comparative Biochemistry and Physiology 83A:613-617.

11. Harding JH (1997) Amphibians and Reptiles of the Great Lakes Region. University of Michigan Press, Ann Arbor, MI.

12. Marshall WS, (2009) Terrestrial locomotion. Online essay. Available at: <http://people.stfx.ca/ bmarshal/201/terrestrialloco.html>.

13. O'Reilly JC, Summers AP, Ritter DA (2000) The evolution of the functional role of trunk muscles during locomotion in adult amphibians. American Zoologist 40:123-135.

14. Brodie ED Jr (1977) Salamander antipredator postures. Copeia 1977:523-535. 